\title{
Experimental study on temperature property along a tunnel axis with flat ceiling in natural ventilation
}

\author{
Yasushi OKA, Hideyuki OKA and Osamu IMAZEKI \\ 1) Faculty of Environment and Information Sciences, Yokohama National University, \\ 79-7 Tokiwadai, Hodogaya-ku, Yokohama, Kanagawa 240-8501, Japan \\ 2) Maritime Risk Assessment Department, National Maritime Research Institute, \\ 6-38-1, Shinkawa, Mitaka, Tokyo 181-0004, Japan \\ 3) I.T. Solutions Department, KAJIMA Corporation, \\ 6-5-30 Akasaka, Minato-ku, Tokyo 107-8502, Japan
}

\begin{abstract}
In this study, detailed measurements of the temperature in a horizontal tunnel with a rectangular cross section were conducted. The temperature decrease along the tunnel axis, the thermal thickness, and the temperature distribution of a steady fire-driven ceiling jet were compared with those for an unconfined smooth-ceiling jet flow. Results of this study showed that the temperature decrease along the tunnel axis was gradual, with the thermal thickness in the tunnel being about two times than that of a ceiling jet under an unconfined ceiling. The temperature distribution in the tunnel exhibits a more bulging shape. Empirical formulae defining the temperature decrease along the tunnel axis, the thermal thickness, and the temperature distribution are also presented.
\end{abstract}

KEYWORDS: ceiling jet, tunnel, temperature decrease, thermal thickness, temperature distribution

\section{NOMENCLATURE LISTING}

\begin{tabular}{|c|c|c|c|}
\hline $\begin{array}{l}a, b, \\
c, d\end{array}$ & $\begin{array}{l}\text { Coefficients in Eq.(4) representing the } \\
\text { temperature distribution as defined by } \\
\text { an exponential function }\end{array}$ & $\begin{array}{l}\Delta T \\
Q_{c} *\end{array}$ & $\begin{array}{l}\text { Temperature rise }[\mathrm{K}] \\
\text { Dimensionless heat release rate [-], } \\
=Q_{c} /\left(\rho_{\infty} C_{p} T_{\infty} g^{1 / 2} H^{5 / 2}\right)\end{array}$ \\
\hline$H$ & Tunnel height $[\mathrm{m}]$ & & \\
\hline$l_{b}$ & Half width of tunnel cross-section [m] & Greek & \\
\hline$h_{b}$ & Beam depth $[\mathrm{m}]$ & $\alpha, \beta$ & Coefficients in Eq.(4) representing \\
\hline$L_{\mathrm{T}}$ & Thermal thickness $[\mathrm{m}]$ & & $\begin{array}{l}\text { the temperature distribution as } \\
\text { defined by a cubic function }\end{array}$ \\
\hline$Q_{\mathrm{C}}$ & Convective heat release rate $[\mathrm{kW}]$ & $\varepsilon$ & Relative error [-] \\
\hline$Q_{\mathrm{t}}$ & Total heat release rate $[\mathrm{kW}]$ & \multicolumn{2}{|c|}{ Subscripts } \\
\hline St & Stanton number [-] & $\mathrm{c}$ & Ceiling \\
\hline$x$ & $\begin{array}{l}\text { Horizontal distance from the point at } \\
\text { which the maximum ceiling gas } \\
\text { temperature appears [m] }\end{array}$ & $\begin{array}{l}\max \\
\infty\end{array}$ & $\begin{array}{l}\text { Maximum } \\
\text { Atmosphere }\end{array}$ \\
\hline$z$ & $\begin{array}{l}\text { Vertical distance from tunnel ceiling } \\
\text { surface }[\mathrm{m}]\end{array}$ & & \\
\hline$z_{\text {apex }}$ & $\begin{array}{l}\text { Distance from the point at which the } \\
\text { vertex of the temperature distribution } \\
\text { appears to the tunnel ceiling }\end{array}$ & & \\
\hline
\end{tabular}

\section{INTRODUCTION}

Road and rail tunnels constitute an important part of the infrastructure that is responsible for passenger and cargo transportation. Over the years, hazard frequency has increased with an increase in the volume of traffic and, in particular, the number of vehicles loaded with combustible materials passing through the tunnels at higher speeds in an effort to reduce transportation times. Fires in tunnels present a serious hazard. Therefore, the localized and early detection of a fire is important for preventing the spread of the fire and implementing a smooth evacuation. 
As the stability of the tunnel structure is a key design parameter relating to the fire safety design of a tunnel, empirical and theoretical correlations were proposed for estimating the maximum ceiling gas temperature and its position, considering the longitudinal ventilation velocity and the shape of the fire source [1-3]. Studies of the critical velocity, which is the velocity of the longitudinal ventilation that prevents the upstream movement of the combustion products from the fire source, have been conducted [4-7]. Some full-scale tests have also been carried out [8-10] and the temperature decrease along the tunnel axis has been reported [11]. Delichatsios [13] reported on the temperature decrease in the ceiling jet flow under a ceiling with beams, as well as the transition to a one-dimensional channel flow from an axi-symmetric case. Koslowski [14] improved on Delichatsios' correlation by introducing a dimensionless temperature rise and the correlation, which is represented as a function of the ratio of the beam depth to the ceiling height. This enhances the application range of the correlation.

Alpert [15] and Heskestad [16] have proposed theories and easy-to-use correlations to quantify the temperature and velocity in the ceiling jet flow at a given position within the ceiling jet which is generated by a steady fire. Motevalli et al. [19] and Cooper [20] have reported on the temperature and velocity distributions of the fire-induced ceiling jet under a smooth, unconfined horizontal ceiling. Oka at al. [17-18, 21-23] developed empirical formulae for representing the decrease in the temperature and velocity, the thermal and momentum thicknesses, and the temperature and velocity distributions perpendicular to the unconfined ceiling. These developed correlations were represented as a function of the angle of inclination of the unconfined ceiling.

As mentioned above, many reports on the ceiling jet, flowing under both unconfined and beamed ceilings, have been published. Extensive studies to characterise the temperature decrease along the tunnel axis have also been conducted. However, insufficient studies have been conducted that focus on the ceiling jet thickness and the temperature distribution within the ceiling jet.

The objective of the current work is then to accurately and systematically measure the temperature properties of the ceiling jet that propagates along the axis of a horizontal tunnel with a smooth, flat ceiling and to develop easy-to-use empirical correlations based on the measured data.

\section{EXPERIMENATL PROCEDURES}

A series of fire tests were conducted in a model tunnel measuring $10.0 \mathrm{~m}(\mathrm{~L}) \times 0.75 \mathrm{~m}(\mathrm{~W}) \times 0.45 \mathrm{~m}(\mathrm{H})$, having the rectangular cross section shown in Figure 1(a). The tunnel ceiling was built using 12-mm calcium silicate boards with a smooth surface finish. Both sidewalls were built using 10-mm transparent poly(methyl methacrylate) (PMMA) board. The floor was built using 9.5-mm plywood, except for the area around the fire source, which was built using 12-mm calcium silicate board. Both ends of the tunnel were left completely open to enable the unrestricted flow of both the current of hot gas flowing out of the tunnel and the fresh air being drawn into the tunnel.

We used two kinds of fuels for our study, one being methanol and the other being liquefied petroleum gas

(LPG, of which propane is a major component). For the methanol, we used two kinds of fuel pans measuring $0.10 \mathrm{~m} \times 0.10 \mathrm{~m}$ and $0.15 \mathrm{~m} \times 0.15 \mathrm{~m}$, both made of stainless steel and 2- $\mathrm{mm}$ - thick. The depth of both pans was $30 \mathrm{~mm}$. The fuel pool was rested on an electric balance (LP 8200S, Sartorius; readability: $0.01 \mathrm{~g}$ ) to measure the mass loss. For the LPG, a predetermined mass was supplied to a diffusion gas burner through a massflow controller (M100B, MKS Instruments). The gas burner was filled with fine porous aggregates. The heat release rates were estimated from the mass loss or flow rate and the heat of combustion of the fuel, relative to the values calculated by assuming complete combustion. The convective heat resulting from the combustion of methanol and LPG (propane) was assumed to be 16.1 and 31.2 $\mathrm{MJ} / \mathrm{kg}$, respectively, while the heat of combustion was 19.1 and $43.7 \mathrm{MJ} / \mathrm{kg}$, respectively [24].

The ceiling gas temperatures resulting from a steady fire source and running along the centre of the ceiling were measured using chromel-alumel (K-type) and copper-constantan (T-type) thermocouples positioned $10 \mathrm{~mm}$ below the tunnel ceiling. The strand diameter of both thermocouples was $0.2 \mathrm{~mm}$. Chromel-alumel thermocouples were set in the near field of the fire source, while copper-constantan thermocouples were set in the far field. These thermocouples were placed at 35 points, every $0.1 \mathrm{~m}$, starting at the centre of the fire source for a distance of $3.5 \mathrm{~m}$ in one direction. In the other direction, thermocouples were installed at 22 points, at 5-, 10-, or $45 \mathrm{~cm}$ intervals depending on the location, up to $6.3 \mathrm{~m}$ from the fire source. 
The temperatures perpendicular to the tunnel ceiling within the ceiling jet running along the centre of the ceiling, as produced by the steady fire source, were measured using thermocouple rakes consisting of Ktype and T-type thermocouples with a strand wire diameter of $0.2 \mathrm{~mm}$. Twelve thermocouples were installed in each thermocouple rake which was oriented from tunnel ceiling to the floor, as shown in Figure 1(b).

The measurement of the temperatures perpendicular to the tunnel ceiling within the ceiling jet was performed twice under the same conditions, firstly with the rake set at four positions $0.75,1.5,3.5$, and 5.5 $\mathrm{m}$ from the fire source centre, described as rake-1. For the second rake, described as rake-2, the thermocouples were set 1.0, 2.0, 3.0, and $4.4 \mathrm{~m}$ from the centre of the fire source. The measured temperatures include the effect of the heat being radiated from the flames as well as that from the heated sides and ceiling of the tunnel. Data on the temperature and mass loss of the fuel were acquired at 1-s intervals by using a data logger (MX110, Yokogawa), and that data were stored on a PC for further analysis. Data collection was started $60 \mathrm{~s}$ before the fuel was ignited. Each test ran for at least $10 \mathrm{~min}$. During the tests, forced ventilation in the laboratory was shut down and all the doors to the test room were closed.

(a)

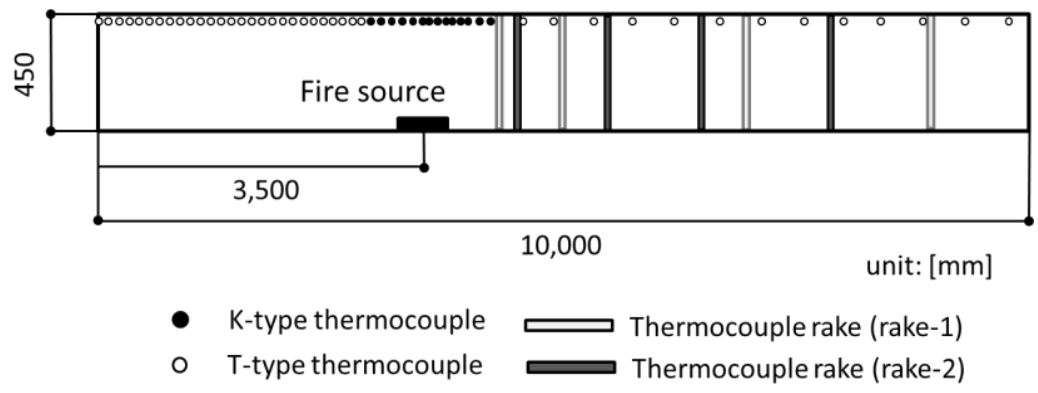

Figure 1 Set up and thermocouple positions (b)

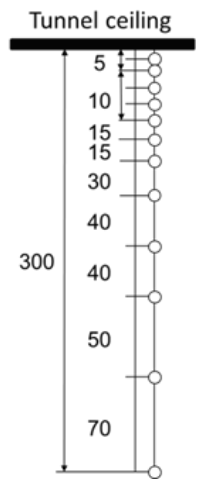

\section{RESULTS AND DISCUSSION}

\section{Heat release rate}

Table 1 presents the results obtained for the heat release rate. The heat release rate when burning methanol was calculated using the Douglas-Avakian numerical differentiation method. The average heat release rate was calculated based on the data obtained during the quasi-steady state existing 420 to $520 \mathrm{~s}$ after ignition. When burning LPG, the heat release rate was adjusted to two different values, namely, $4.48 \mathrm{~kW}$ and 8.89 $\mathrm{kW}$. Applying this to a full-scale tunnel with a height of $7 \mathrm{~m}$, the heat release rate range employed in this experiment (3.40-8.89 kW) would correspond to a range of 3.2-8.5 MW, as calculated from Froude modelling. This range of the values would be generated by a passenger vehicle fire.

Table 1 Heat release rates used in this study

\begin{tabular}{|c|c|c|c|}
\hline Fuel type & $\begin{array}{c}\text { Size of } \\
\text { fuel pan or gas burner }\end{array}$ & $Q_{\mathrm{t}}[\mathrm{kW}]$ & $\mathrm{TC}$ rake position \\
\hline \multirow{5}{*}{ Methanol } & \multirow{3}{*}{$0.10 \mathrm{~m} \mathrm{sq}$. } & 3.40 & rake-1 \\
\hline & & 3.46 & rake-1 \\
\hline & & 3.63 & rake-2 \\
\hline & \multirow{2}{*}{$0.15 \mathrm{~m} \mathrm{sq}$. } & 8.02 & rake-1 \\
\hline & & 7.90 & rake-2 \\
\hline \multirow{2}{*}{ LPG } & \multirow{2}{*}{$0.10 \mathrm{~m}$ sq. } & 4.48 & rake-2 \\
\hline & & 8.89 & rake-2 \\
\hline
\end{tabular}



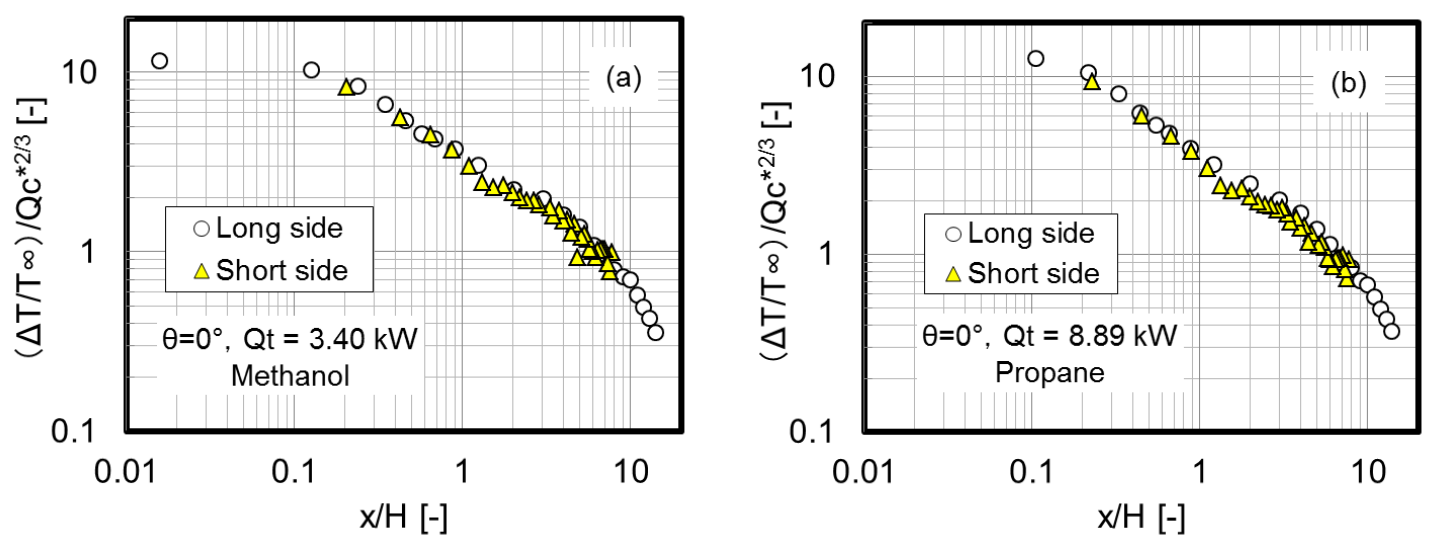

Figure 2 Effect of fire source position on ceiling jet flow
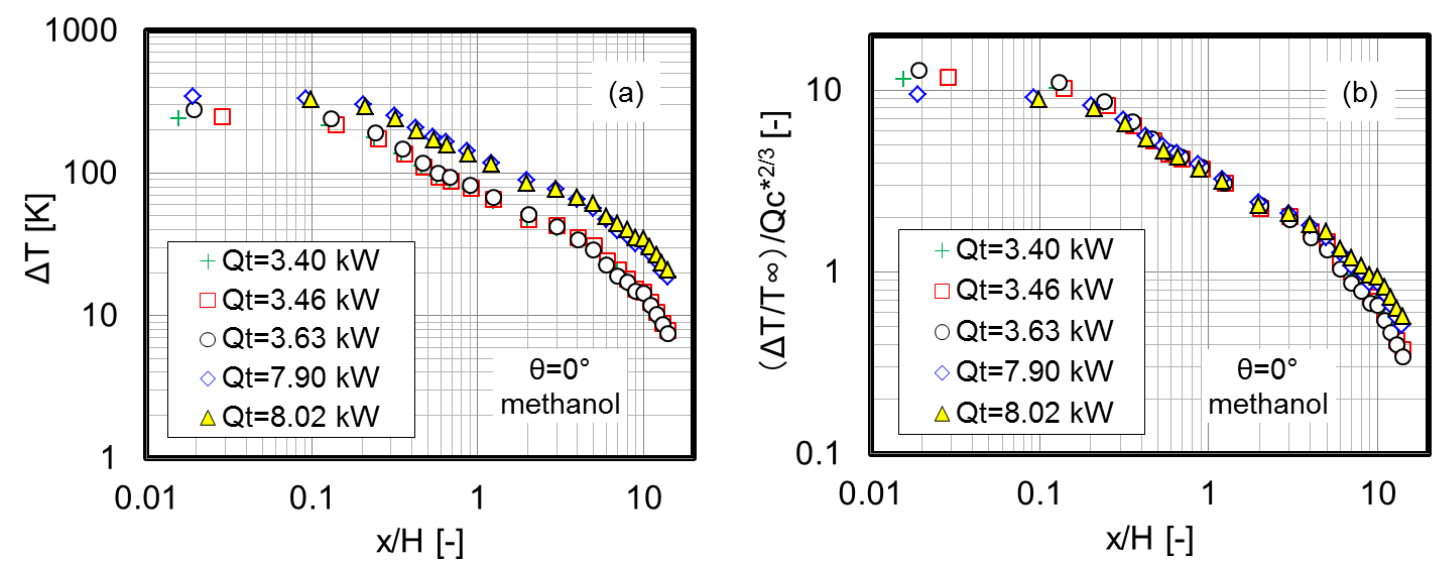

Figure 3 Variation of temperature rise with distance in horizontal tunnel

\section{Temperature decrease along the tunnel axis}

The position of the fire source has little influence of the flow properties, as shown in Figure 2. In all of the experiments, the ceiling jet flow was confirmed as being symmetrical along the horizontal tunnel axis, regardless of both the heat release rate and the fuel type.

Figure 3(a) shows the ceiling gas temperature decrease along the horizontal tunnel axis. In this case, the fuel is methanol. The reproducibility can be confirmed. By converting this to a dimensionless temperature rise, all of the data can be coalesced into the single curve shown in Figure 3(b).

Figure 4(a) shows a comparison of the rise in the ceiling gas temperature with Oka's correlation [17], which was developed assuming that the flames do not touch the horizontal unconfined ceiling. Within the range up to $x / H=1$, which almost corresponds to the axisymmetric radial turbulent jet region, the ceiling gas temperature in the tunnel is slightly higher than that under an unconfined ceiling. There is a possibility, however, of representing the temperature decrease with the distance by adjusting the values of the constants in Oka's correlation. For the range in excess of $x / H=1$, the ceiling gas temperature in the tunnel is much higher than that under an unconfined ceiling and exhibits a different temperature decay dependence on the distance. Figure 4(b) shows a comparison of the ceiling gas temperature rise with Koslowski's correlation [14] for a flow under a beamed ceiling. The pre-exponential factor is incorporated into Koslowski's correlation. This variable points to the dependence on $h_{\mathrm{b}} / H$, the ratio of the beam depth to the ceiling height, which is given by a quadratic function. The applicable range varies from 0.07 to 0.28 based on the experimental data. To apply Koslowski's correlation to the tunnel, the maximum value of $h_{\mathrm{b}} / H=0.28$ was assigned to the pre-exponential factor. The application range for Koslowski's correlation is $0.5 \leq x / H \leq 1.6$ while that for Oka's correlation is $0.4 \leq x / H \leq 5.8$. 

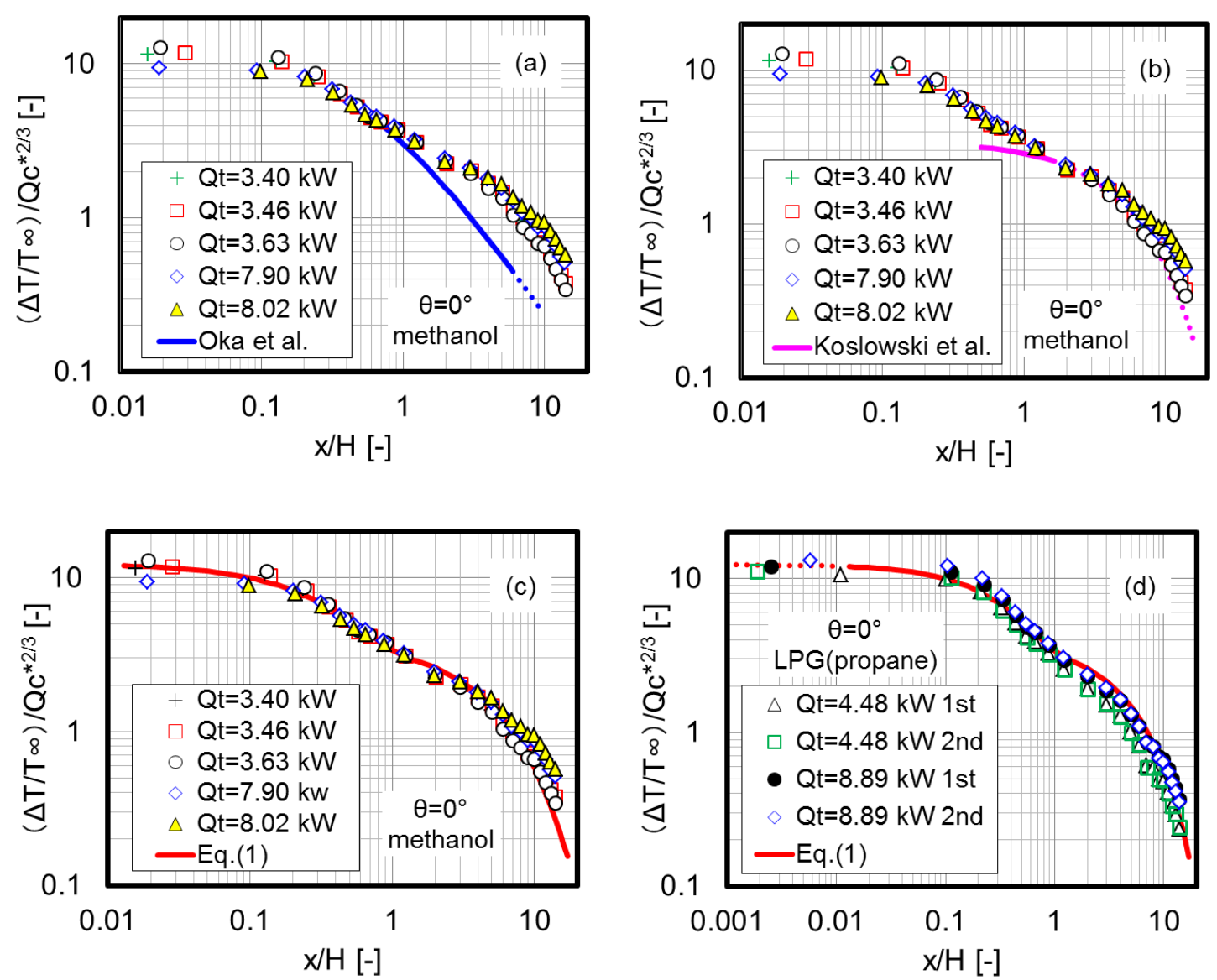

Figure 4 Variation of ceiling gas temperature rise with distance in horizontal tunnel

Within the range up to $x / H=1$, the estimated temperature is much lower. For the range in excess of $x / H=1$, however, the temperature decrease relative to the distance exhibits a similar tendency, although the entrainment mechanism for the ambient air is not exactly the same in a tunnel and under a beamed ceiling.

As pointed out by Delichatsios [13], the temperature decrease can be identified for three flow regions, namely, (1) Region I: the axisymmetric radial turbulent jet region, (2) Region II: the flow transition region, and (3) Region III: fully developed one-dimensional channel flow region, shown in Figure 5. The empirical formulae given by Eq. (1) were developed by combining the existing temperature decrease correlations that had already been proposed for Regions I and III. For Region II, we developed a new correlation by referring to Delichatsios' approximate technique [13] instead of Alpert's theory for the radial spread region and by referring to Li's approach [11] for the region where the radial spread transitions to a onedimensional channel flow region, assuming the ceiling wall friction and heat transfer to be negligible. The coefficients for each correlation were newly determined based on a comparison between the experimental results obtained when using methanol as the fuel. The Stanton number of 0.03 is in line with Delichatsios' suggestion. The data with the newly developed empirical correlation given in Eq.(1) are displayed for comparison in Figure 4(c). Here, 0.833 is the ratio of the half-width of the tunnel cross section to the tunnel height, namely, $l_{b} / H$. Figure 4(d) shows a comparison of Eq. (1) with the data obtained when using LPG as the fuel. We confirmed that the data and equation were consistent.

The magnitude of the Stanton number affects the temperature reduction along the tunnel axis. Li [26] pointed out that the value of the Stanton number as estimated by Delichatsios may be excessive and that Kunsch's value is more appropriate for a tunnel. This should be examined prior to any practical application. 


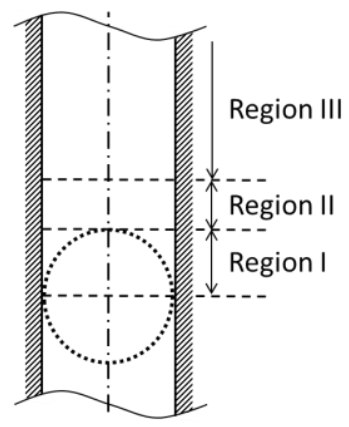

(a) top view

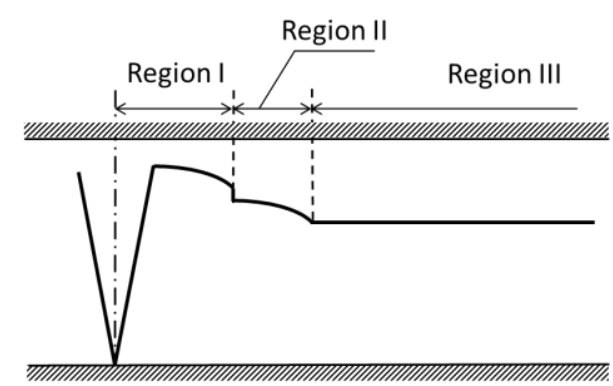

(b) side view

Figure 5 Schematic diagram of ceiling jet in horizontal tunnel

$$
\begin{array}{ll}
0.016 \leq x / H<0.833 & \frac{\Delta T / T_{\infty}}{Q_{C}^{* 2 / 3}}=\left(0.152+0.263 \frac{x}{H}\right)^{-4 / 3} \\
0.833 \leq x / H<1.266 & \frac{\Delta T / T_{\infty}}{Q_{C}^{* 2 / 3}}=3.528\left(\frac{H}{l_{b}}\right)^{1 / 3}\left[1+1.408\left(\frac{l_{b}}{H}\right)^{1 / 3}\left(\frac{x}{H}-\frac{l_{b}}{H}\right)\right]^{-1 / 2} \\
1.266 \leq x / H & \frac{\Delta T / T_{\infty}}{{ }^{* 2 / 3}}=3.57\left(\frac{H}{l_{b}}\right)^{1 / 3} \exp \left[-6.67 S t \frac{x}{H}\left(\frac{l_{b}}{H}\right)^{1 / 3}\right]
\end{array}
$$

\section{Thermal thickness}

The ceiling jet is characterised as a function of the respective maximum value: the vertical distance from the ceiling, $z$; and the distance from the plume impingement point, $x$, (i.e. $\Delta T(x, z)$ ). The key parameters that define the ceiling jet behaviour as a function of its position under steady-state conditions are shown in Figure 6 . The ceiling jet thermal boundary layer thickness is denoted as $\delta T_{\max }$. This identifies that region of the ceiling jet in which the temperature varies from that at the wall to the maximum value, $\Delta T_{\max }$. The thermal thickness, $L_{\mathrm{T}}$, is represented as the sum of the thermal boundary layer thickness and the distance from the maximum point to that point at which the temperature rise above the ambient value drops to $1 / e$ of the maximum temperature rise.

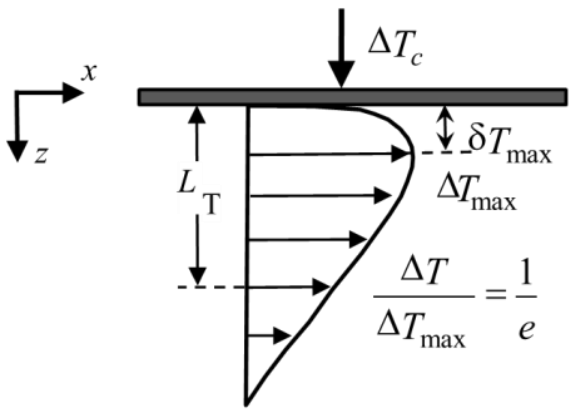

temperature distribution $\Delta T(x, z)$

Figure 6 Schematic of ceiling jet and its characteristic parameters 

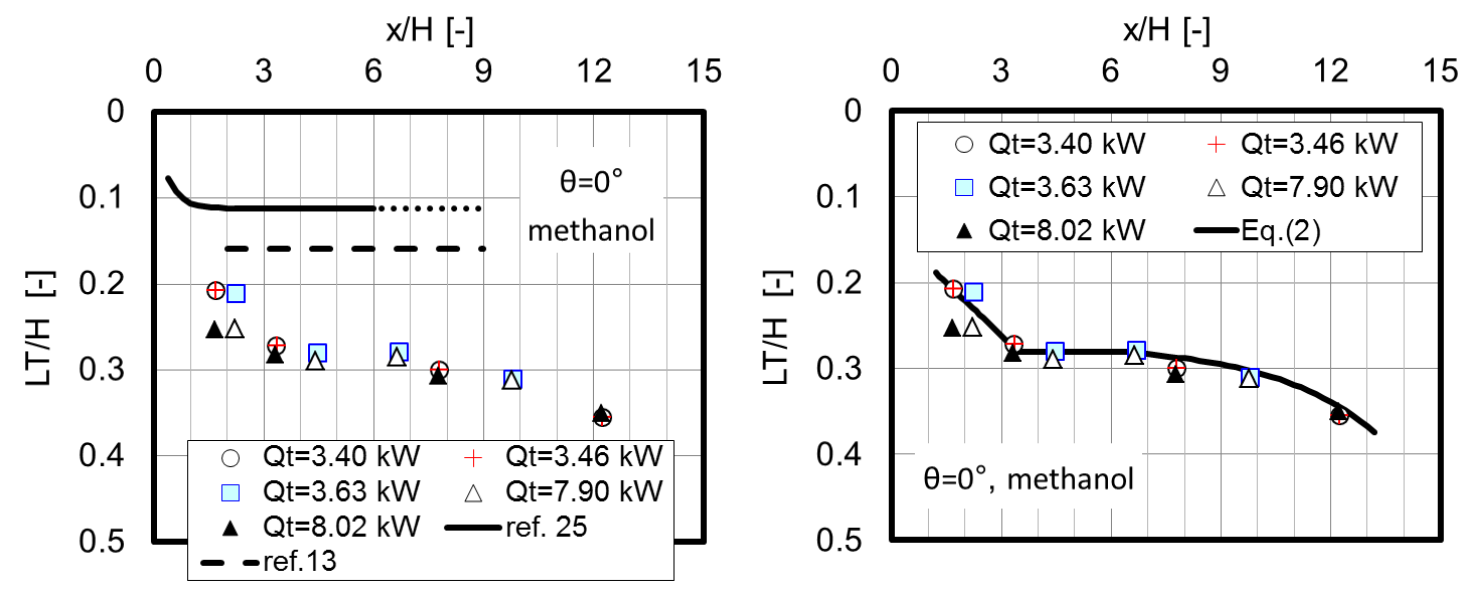

Figure 7 Relationship between thermal thickness and distance from fire source in tunnel.

(a) Comparison with existing correlation for unconfined horizontal ceiling

(b) Comparison with newly developed correlation

Instead of directly reading the maximum temperature rise from the measured temperature distribution, the estimated maximum temperature and its position, based on a quadratic fit to the measured data for three points, including the maximum vertical temperature, were employed. The position, which was $1 / e$ of the estimated maximum temperature rise, was estimated by applying a straight-line approximation to three measured points holding the $1 / e$ position of the maximum temperature.

According to the results obtained for the thermal thickness of the ceiling jet flow under an unconfined ceiling [25], when the heat release rate was changed from 20.5 to $90.2 \mathrm{~kW}$ and the ceiling height was varied between 0.94 and $2.78 \mathrm{~m}$, the thermal thickness of the ceiling jet was almost constant within the range of $x / H=2$ to 6 . It gradually became thicker in the region in excess of $x / H=6$.

The thermal thickness of the ceiling jet in a horizontal tunnel shows a similar tendency to the results obtained for an unconfined ceiling. Figure 7 shows the dependency of the thermal thickness of the ceiling jet on the distance from the plume impingement point. The thermal thickness of the ceiling jet increases as the distance increases within the region of about $x / H=3$ or less and comes close to being almost constant around the region from $x / H=3$ to about $x / H=7$. The thermal thickness of the ceiling jet in this region is about $28 \%$ of the tunnel height. It is well known that the thermal thickness of the ceiling jet under an unconfined smooth horizontal ceiling is about 10 to $12 \%$ of the ceiling height. Then, that in a tunnel is about 2.5 times thicker because the fire gases are restricted by the sidewalls of the tunnel. Our data also show a thicker ceiling jet than that for the channel flow theoretically derived by Delichatsios [13].

In the region where $x / H=7$ or more, the thermal thickness of the ceiling jet gradually increases. The temperature distribution within the ceiling jet is thought to exhibit a gradual distribution as a result of the temperature reduction and thermal diffusion.

Hence, we set three regions to represent the thermal thickness dependence on the distance from the fire source. The three regions were as follows: in the first region, the thermal thickness of the ceiling jet increases linearly with the distance from the fire source; in the second region, the thermal thickness is constant regardless of the distance; in the third region, the thermal thickness increases exponentially with the distance from the fire source. The values of the coefficients in Eq. (2) were determined based on a limited amount of measured data. Then, it should be noted that these values may change after new data are added in the future. 


$$
\begin{aligned}
1.69 \leq x / H<3.45 & \frac{L_{T}}{H} & =0.04080\left(\frac{x}{H}-\frac{l_{b}}{H}\right)+0.1632\left(\frac{l_{b}}{H}\right)^{-1 / 3} \\
3.45 \leq x / H<6.8 & \frac{L_{T}}{H} & =0.2636\left(\frac{l_{b}}{H}\right)^{-1 / 3} \\
6.8 \leq x / H & \frac{L_{T}}{H} & =0.2802+0.01021 \exp \left\{0.3598\left(\frac{x}{H}-6.8\right)\right\}-0.007656
\end{aligned}
$$

\section{Temperature distribution}

Figures 8(a) and 8(c) show a typical temperature distribution in the direction perpendicular to the tunnel ceiling. Under each experimental condition, the temperature distribution exhibits a convex shape with the maximum temperature rise at the apex. As the position of the apex gradually moves towards the tunnel floor and the maximum temperature rise decreases as the distance from the fire source increases, the convex temperature distribution changes to a gradually decreasing distribution. To eliminate the influence of the difference in distribution shape with the distance, the temperature rise and perpendicular distance from the ceiling were normalised by dividing them by the maximum temperature rise, $\Delta T_{\max }$, and the thermal thickness, $L_{\mathrm{T}}$, respectively, at each point where the temperature distributions were measured. The normalised temperature distribution was found to coalesce to the same line independently of the distance from the fire source. This tendency persisted, regardless of the heat release rate, as shown in Figures $8(\mathrm{~b})$ and $8(d)$.

Figure 9 shows a comparison of the measured and predicted temperature distributions, relative to the previous correlations devised by Motevalli \& Marks [19], Cooper [20], and Oka et al. [21, 22]. Motevalli and Marks, and Cooper, represented the temperature distribution, at a given radial distance within a ceiling jet flowing under a smooth horizontal unconfined ceiling, by applying either an exponential function or a trigonometric function, respectively. Oka et al. represented the temperature distribution by applying either an exponential function or a cubic function and the coordinate transformation that took into account the inclination angle of the unconfined ceiling. As shown in Figure 9, the temperature distribution within the ceiling jet in the horizontal tunnel exhibits a more bulging shape than that under an unconfined ceiling. The data obtained for the tunnel exhibit a property whereby the temperature decreases more slowly from the position at which the temperature is a maximum, although the correlations devised by Cooper [20] and Oka et al. [22] were devised to represent this swelling of temperature distribution.

Figure 10 shows a comparison of the relative error, as calculated with Eq. (3) between the temperature distribution obtained with the existing correlations and the measured data. The compared range was $0<$ $z / L_{\mathrm{T}}<1$. The correlations devised by Cooper [20] and Oka et al. [22] exhibit a small error than those devised by Motevalli and Marks [19] and Oka et al. [21]. Cooper's and Oka et al.'s correlations were improved to represent the swelling in the temperature distribution based on the exponential approximation. Although the relative error between the measured and predicted values, based on Ref. 22, is no more than $5 \%$, a further improvement is necessary to improve the accuracy. 

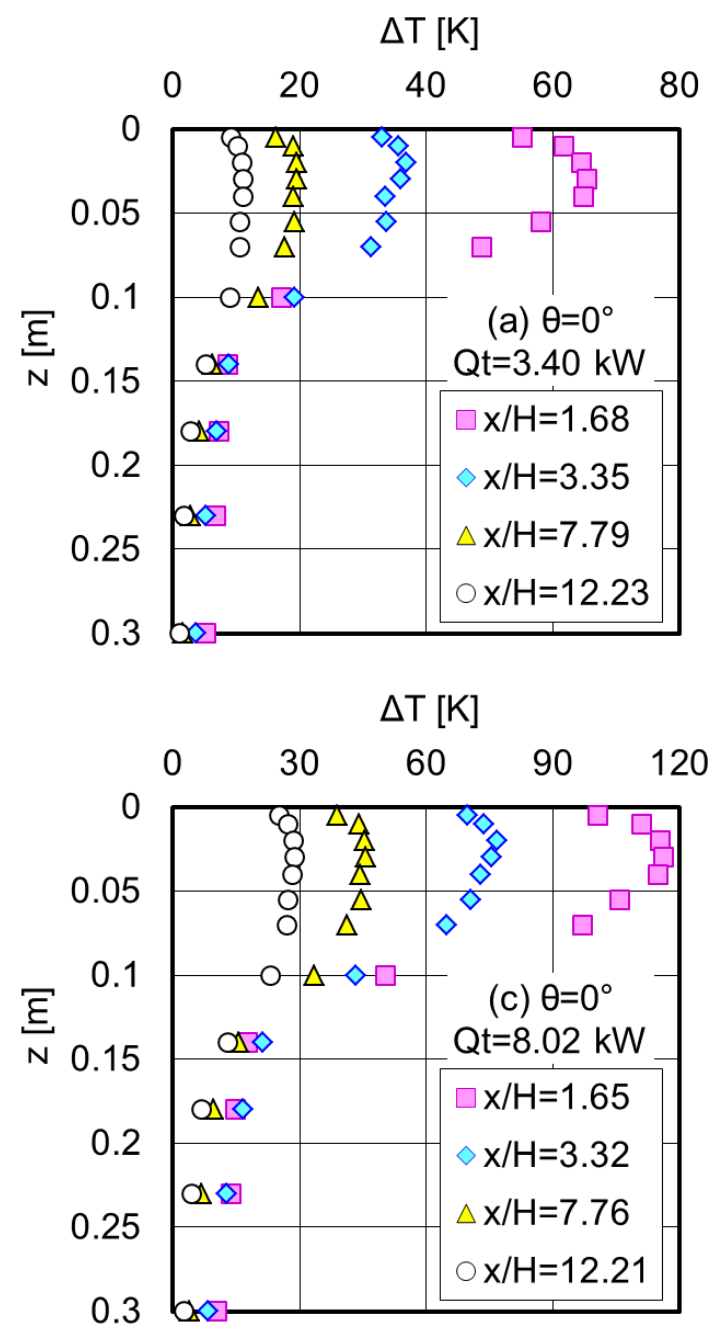
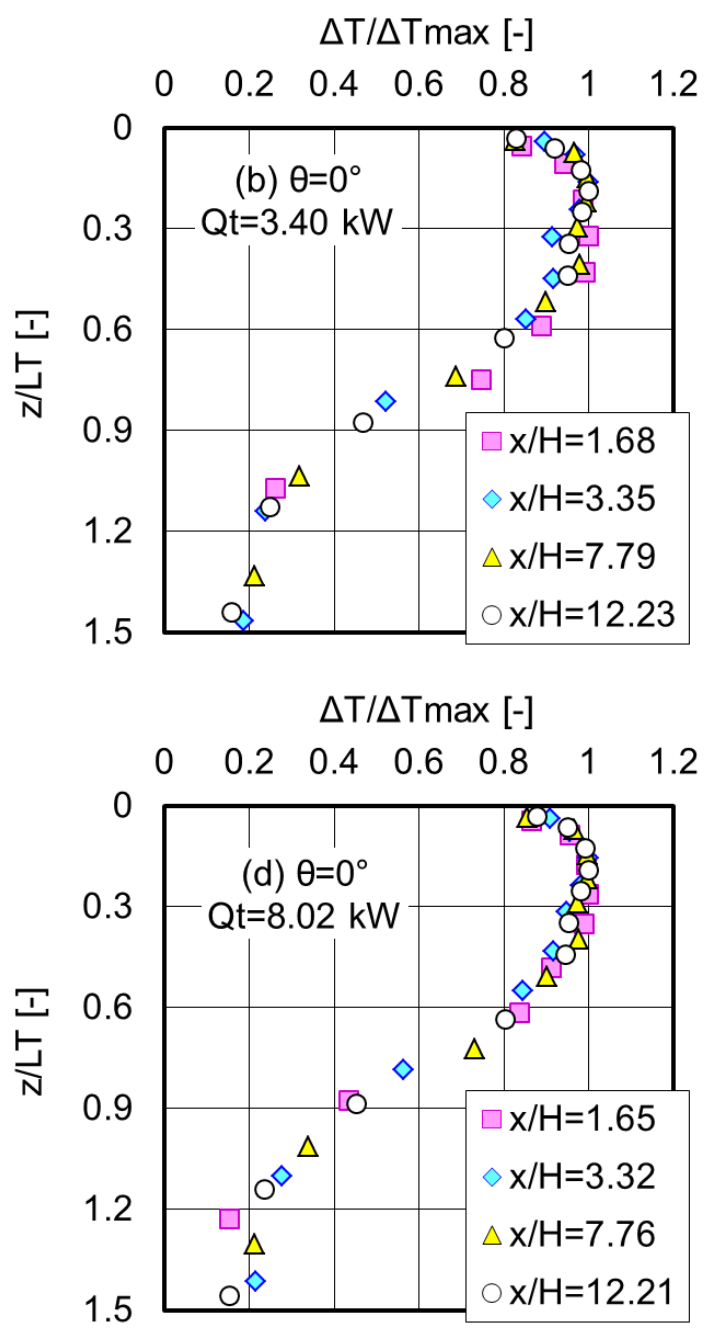

Figure 8 Temperature distribution in direction perpendicular to the tunnel ceiling

Nomal temperature distributions: (a) and (c), normalised temperature distributions: (b) and (d)

$\varepsilon=\sqrt{\frac{1}{n} \sum_{i=1}^{n}\left(x_{i}-y_{i}\right)^{2}} / \frac{1}{n} \sum_{i=1}^{n} y_{i}$

Then, the modified correlations representing the temperature distribution are shown in Figure 11 and given by Eq. (4). Figure 12 shows a schematic of the coordinate system. 
$\Delta \mathrm{T} / \Delta \mathrm{T} \max [-]$

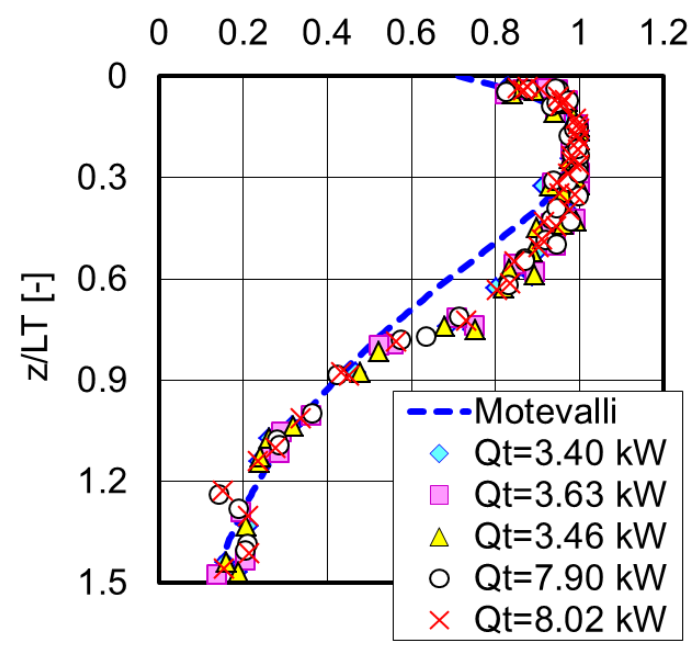

$\Delta \mathrm{T} / \Delta \mathrm{T} \max [-]$

$\begin{array}{lllllll}0 & 0.2 & 0.4 & 0.6 & 0.8 & 1 & 1.2\end{array}$

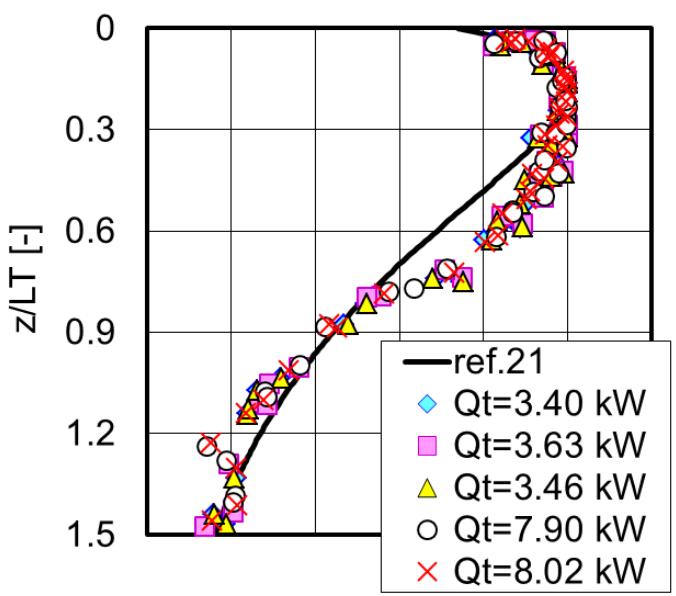

$\Delta \mathrm{T} / \Delta \mathrm{T} \max [-]$

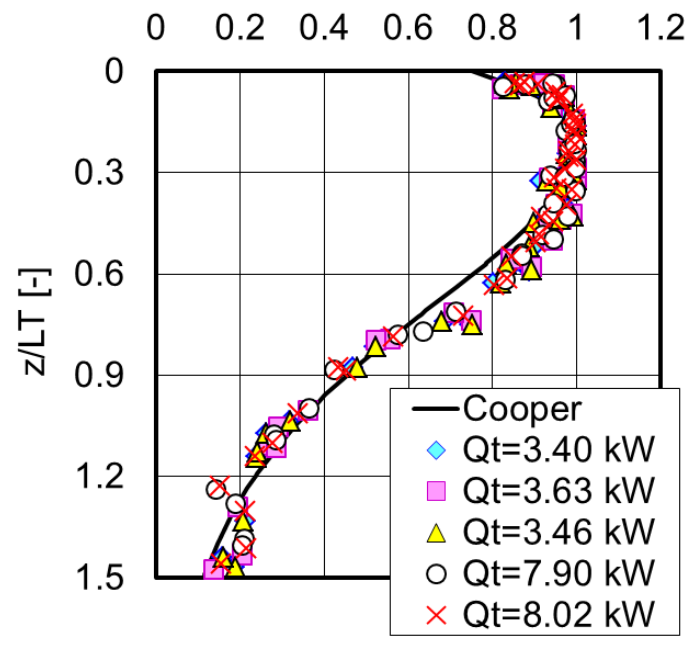

$\Delta \mathrm{T} / \Delta \mathrm{T} \max [-]$

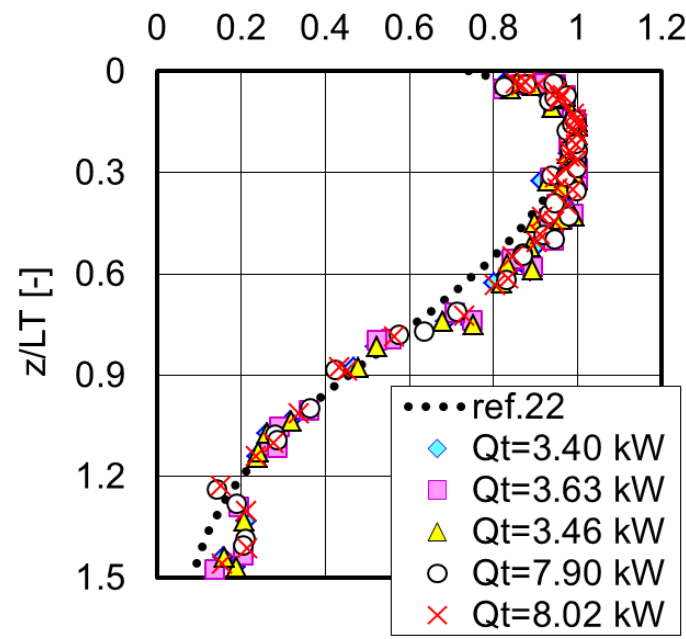

Figure 9 Comparison between existing correlations and measured data

$z / L_{T}<z_{\text {apex }}$

$\frac{\Delta T}{\Delta T_{\max }}=a\left(\frac{z}{L_{T}}+b\right)^{c} \exp \left(-d \frac{z}{L_{T}}\right)$

$a=3.033, b=0.06566, c=0.5185, d=2.1208, z_{\mathrm{apex}}=c / d-b$

$z / L_{T} \geq z_{\text {apex }}$

$Y=\alpha X(X+\beta)(X-\beta), \beta \geq 0$

$\left[\begin{array}{c}z / L_{T} \\ \Delta T / \Delta T_{\max }\end{array}\right]=\left[\begin{array}{cc}\cos \varphi & -\sin \varphi \\ \sin \varphi & \cos \varphi\end{array}\right]\left[\begin{array}{l}X \\ Y\end{array}\right]+\left[\begin{array}{l}x_{0} \\ y_{0}\end{array}\right]$

$\alpha=0.6178, \beta=\sqrt{\left(x_{0}-z_{\text {apex }}\right)^{2}+\left(y_{0}-1\right)^{2}}, x_{0}=0.7964, y_{0}=0.5788$

$\cos \varphi=\left(x_{0}-z_{\text {apex }}\right) / \beta, \sin \varphi=\left(y_{0}-1\right) / \beta$ 


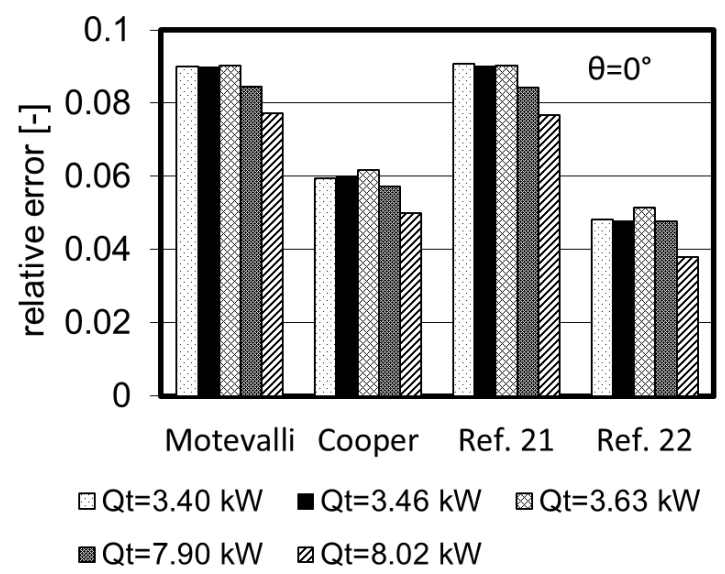

Figure 10 Comparison of relative error between measured and predicted values
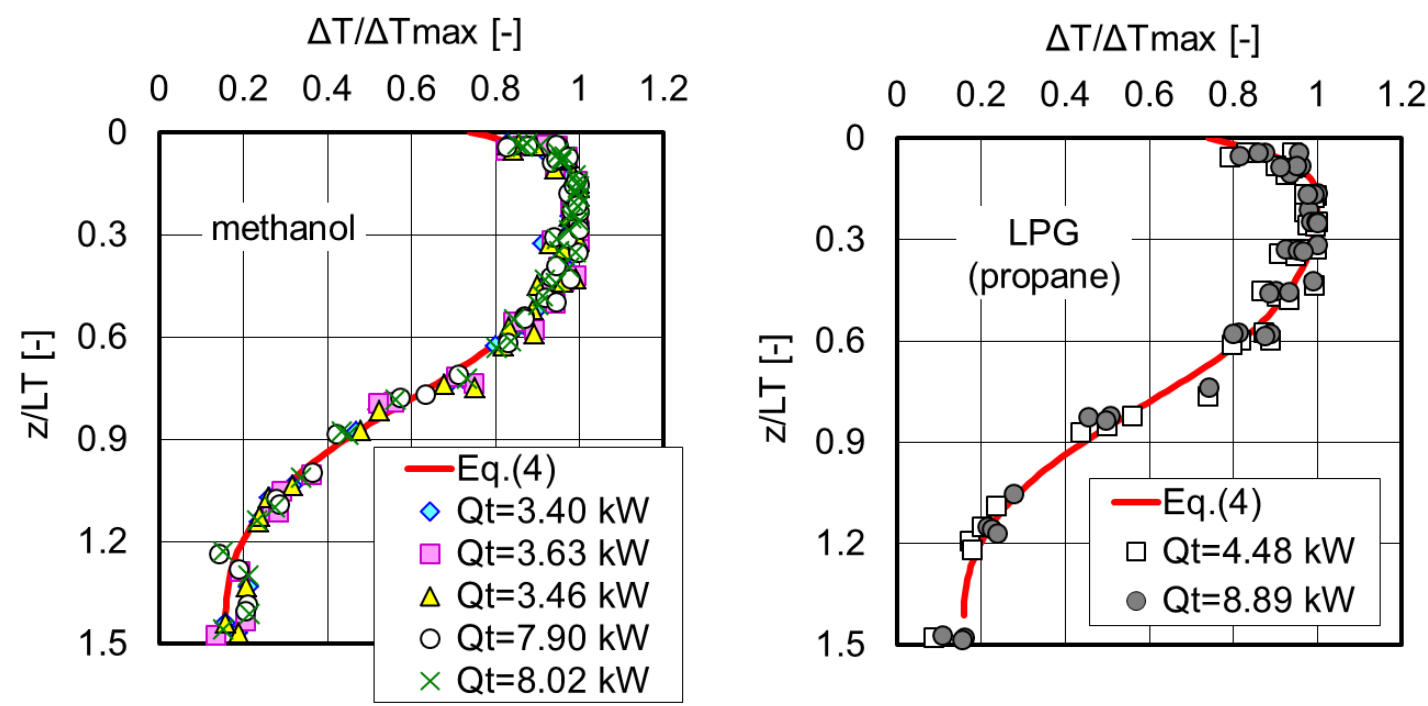

Figure 11 Comparison of measured and newly developed correlations for temperature distribution

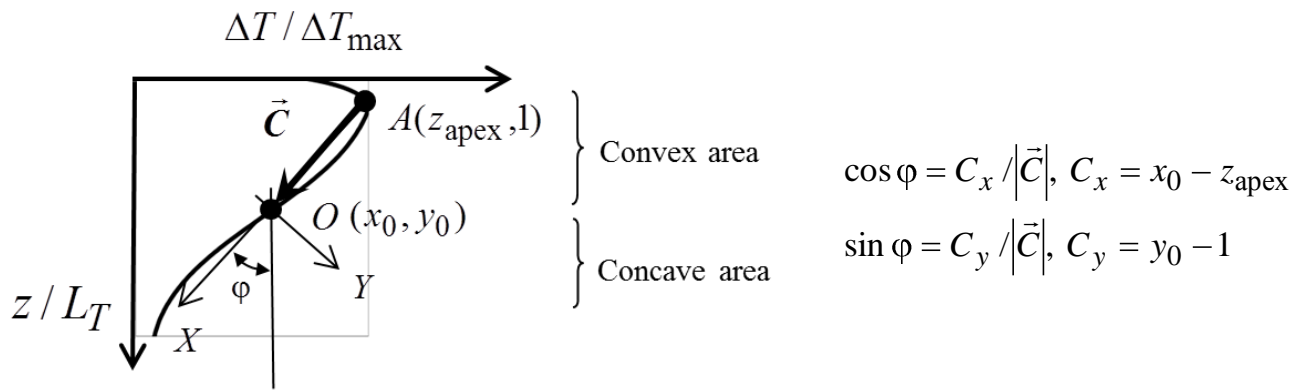

Figure 12 Schematic of coordinate system 
Figure 13 shows a comparison of the temperature distribution in a full-scale tunnel and the proposed correlation given by Eq. (4). Two kinds of temperature distributions were obtained from the literature [27]. One was $1 / 3$ scaled small road tunnel for passenger cars, $1.93 \mathrm{~m}$ wide and $1.0 \mathrm{~m}$ height; the other was an ordinary road tunnel, $9.8 \mathrm{~m}$ wide and $4.7 \mathrm{~m}$ height. The temperature distributions were measured at distances of $27 \mathrm{~m}$ and $80 \mathrm{~m}$ from the fire source. Although the temperature in the vicinity of the tunnel ceiling was not measured and the temperature measurement interval was rough, we confirmed that the temperature distributions in the full-scale tunnels coalesce on the line represented by Eq. (4).

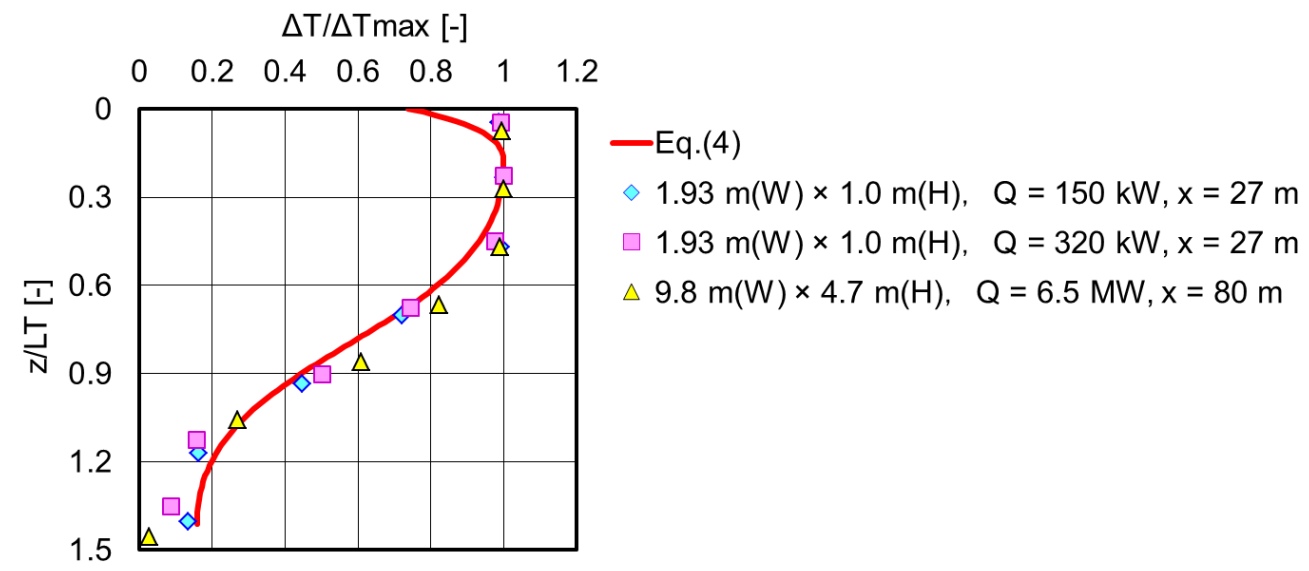

Figure 13 Comparison of measured full-scale road tunnel and Eq. (4) for temperature distribution

\section{CONCLUSIONS}

A series of tests were conducted to investigate the temperature properties of the ceiling jet in a horizontal model tunnel having a rectangular cross section. Our conclusions were as follows:

1) The temperature decrease along the axis of the tunnel shows different properties depending on the distance from the plume impingement point. In the region up to $x / H=1$, the temperature decrease shows a similar dependence to that under an unconfined ceiling, while in the range of $x / H=2$ or more, the dependence resembles that of the ceiling jet flow when restricted by a beamed ceiling.

2) An empirical relationship to estimate the decrease in the ceiling jet temperature along the horizontal axis of the tunnel was developed by combining the correlations for ceiling jet flows that were derived under an unconfined ceiling, within the transition region, and for a beamed ceiling configuration.

3) The thermal thickness of the ceiling jet in a horizontal tunnel is 2.5 times that under an unconfined ceiling, and is 1.7 times the value obtained with the theoretical derived correlation. An empirical formula was developed.

4) The temperature distribution in a direction perpendicular to the tunnel ceiling exhibits a more bulging shape than that of a ceiling jet under an unconfined ceiling.

5) The correlation, which is composed of a cubic function and a coordinate transformation, can approximate the temperature distribution within a relative error range of 5\%. A modified correlation was established in order to increase the accuracy further.

\section{ACKNOWLEDGEMENT}

This research was conducted with the support of the Joint Usage/Joint Research Centre of the "Research Center for Fire Safety Sciences”, the Center for Fire Science and Technology, Tokyo University of Science. Part of this work was conducted under the support of the Grants-in-Aid for Scientific Research (Basic research B, No.23310108). The authors would like to thank Mr. Kosuke Nozawa and Ms. Kyoko Kamiya, graduate students of Yokohama National University, for their help in carrying out the experiments. 


\section{REFERENCES}

[1] Kurioka, H., Oka, Y., Satoh, H., and Sugawa, O., "Fire Properties in Near Field of Fire Source with Longitudinal Ventilation in Tunnels", Fire Safety Journal, vol.38, No.4, pp.319-340, 2003.

[2] Oka, Y., and Kurioka, H., "Effect of Shape and Size of a Fire Source on Fire Properties in Vicinity of a Fire Source in a Tunnel”, Journal of Fire Science and Technology, vol.25, No.1, pp.15-29, 2006.

[3] Li, Y. Z. and Ingason, H., "The Maximum Ceiling Gas Temperature in a Large Tunnel Fire”, Fire Safety Journal, vol.48, pp.38-48, 2012.

[4] Oka, Y., and Atkinson, G.: "Control of Smoke Flow in Tunnel Fires", Fire Safety Journal, vol.25, No.4, pp.305-322, 1995.

[5] Atkinson, G.T., and Wu, Y., "Smoke Control in Sloping Tunnels", Fire Safety Journal, vol.27, No.4, pp.335-341, 1996.

[6] Kunsch, J.P., "Critical Velocity and Range of Fire-gas Plume in a Ventilated Tunnel", Atmospheric Environment, vol.33, pp.12-24, 1999.

[7] Kunsch, J.P., "Simple Model for Control of Fire Gases in a Ventilated Tunnel", Fire Safety Journal, vol.37, pp.67-81, 2002.

[8] Bettis, R. J., Jagger, S. F. and Macmillan, A. J. R., "Interim Validation of Tunnel Fire Consequence Models; Summary of Phase 1 Tests", HSL Report IR/L/FR/94/2, (1994)

[9] Bettis, R. J., Jagger, S. F. and Wu, Y., "Interim Validation of Tunnel Fire Consequence Models; Summary of Phase 2 Tests", HSL Report IR/L/FR/93/11, (1993)

[10] Grant, G.B., Jagger, S.F. and Lea, C.J., "Fires in Tunnels", Philosophical Transactions of the Royal Society of London A, vol.256, pp.2873-2906, 1998.

[11] Li, S., Zong, R, Zhao, W., Yan, Z. and Liao, G., "Theoretical and Experimental Analysis of Ceiling-jet Flow in Corridor Fires", Tunneling and Underground Space Technology, vol.26, pp.651-658, 2011.

[12] Hu, L.H., Huo, R., Wang, H.B., Li, Y.Z., and Yang, R.X., "Experimental Studies on Fire-induced Buoyant Smoke Temperature Distribution along Tunnel Ceiling”, Building and Environment, vol. 42, pp.3905-3915, 2007.

[13] Delichatsios, M.A., "The Flow of Fire Gases under a Beamed Ceiling”, Combustion and Flame, vol.43, pp.1-10, 1981.

[14] Koslowski, C.C. and Motervalli, V., "Behavior of a 2-Dimensional Ceiling Jet Flow: A Beamed Ceiling Configuration", Fire Safety and Science, Proceedings of the Fourth International Symposium, International Association for Fire Safety Science, pp.469-480, 1994.

[15] Alpert, R.L., "Fire Induced Turbulent Ceiling Jet", Technical Report, Factory Mutual Research Corp., FMRC Serial No. 1972-2, 1971.

[16] Heskestad, G. and Delichatsios, M.A., "The initial Convective Flow in Fire", Proceedings of the 17th International Symposium on Combustion, pp.1113-1123, The Combustion Institute, 1978.

[17] Oka, Y., and Ando, M., "Temperature and Velocity Decreasing Property of Ceiling Jet Impinged on an Unconfined Inclined Ceiling”, Fire Safety Journal, vol.55, pp.97-105, 2013.

[18] Oka,Y., Ando, M., and Kamiya, K, "Ceiling Jet Flow Property in the Case of Flame Touching an Inclined Ceiling", Fire Safety and Science, Proceedings of the 10th International Symposium, International Association for Fire Safety Science, pp.471-482, 2011.

[19] Motevalli, V., and Marks, C.H., "Characterizing the Unconfined Ceiling Jet under Steady-State Conditions: A Reassessment", Fire Safety Science-Proceedings of the Third International Symposium, pp.301-312, 1991. 
[20] Cooper, L.Y., “Ceiling Jet-driven Wall Flows in Compartment Fires”, NBSIR 87-3535, 1987.

[21] Oka, Y. and Imazeki, O., “Temperature and Velocity Distributions of Ceiling Jet along an Inclined Ceiling - Part 1: Approximation with Exponential Function -", in press.

[22] Oka, Y. and Imazeki, O., "Temperature and Velocity Distributions of Ceiling Jet along an Inclined Ceiling - Part 2 : approximation based on cubic function and coordinate transformation -", submitted to Fire Safety Journal

[23] Oka, Y., Ando, M., and Imazeki, O., "Study on Ceiling Jet Thickness under an Inclined Ceiling", Proceedings of 6th International Seminar on Fire and Explosion Hazards, pp.185-196, 2010.

[24] Tewarson, A., "Generation of Heat and Gaseous, Liquid, and Solid Products in Fires", The SFPE Handbook of Fire Protection Engineering, Fourth Edition, Section 3, Chapter 4, pp.3-166, 2008.

[25] Oka, Y., and Matsuyama, K., "Scale Similarity on Ceiling Jet Flow”, Fire Safety Journal, vol.61, pp.289-297, 2013.

[26] Li, L., Cheng, X., Wang, C., and Zhang, H., “Temperature Distribution of Fire-induced Flow along Tunnels under Natural Ventilation”, Journal of Fire Sciences, vol.30, No.2, pp.122-137, 2012.

[27] Kikumoto, T., Kawabata, N., Maruyama, D., and Yamada, M., "Model Tests on Fire Smoke Behavior in a Small Road Tunnel for Passenger Cars", Journal of Japan Society of Civil Engineers, division F, vol.63, No.3, pp.361-373, 2007. in Japanese. 